\title{
Affinity analysis using apriori algorithm to identify failure dependence in multi- component systems
}

\author{
R. S. Lopes*, Phuc Do**, C.A.V. Cavalcante* and Benoit Iung ** \\ *r.s.lopes@random.org.br \\ **phuc.do@univ-lorraine.fr \\ *c.a.v.cavalcante@random.org.br \\ **Benoit.Iung@univ-lorraine.fr \\ * Federal University of Pernambuco, RANDOM - Research Group on Risk and Decision Analysis in Operations and \\ Maintenance, Department of Production Engineering, UFPE, Brazil \\ ** Université de Lorraine, CRAN, UMR 7039, Campus Sciences, BP 70239, Vandoeuvre-Les-Nancy, 54506, France
}

\begin{abstract}
Maintenance decisions in multi-component systems are of great interest to maintenance managers. The equipment during its operation, produces and stores a large amount of data, especially discrete event data such as alarm, failed situation, change of operation modes, stop of the systems, and so forth, and produced via processings supported by the programmable logic controller (PLCs), supervision system, SCADA. Considering this data to assist in maintenance management and decisions is an area with a growing interest in maintenance management. In this paper, we study the stochastic dependency in a multi-component system through data from PLCs database. We use appriory algorithm and affinity function to identify failure dependence in multi-component systems. The results of failure dependence can be used as input for planning group maintenance, purchase spare parts, or planning opportunistic maintenance.
\end{abstract}

\section{Introduction}

The reliability of the systems is of significant importance to every production process. The ability to keep systems available at a resealable cost is a great challenge for maintenance managers. Models that define maintenance actions and evaluate systems reliability have been successfully applied in various systems, like energy (Zhang et. al. 2019), transport (Erdoğan and İhsan Kaya 2020), mining industry (Kalinowski et. al. 2019), food process (Yavuz et. al 2019), and chemical process (Vianello et al 2020).

In the past decade, there has been a growing interest in evaluating maintenance actions in multi-component systems, with the development of maintenance models considers component complexity and dependencies (Dong et al 2019). There are three kinds of component dependencies in a complex system: stochastic dependence, structural dependence, and economic dependence. In a structural dependency, for a system to be maintained is necessary to replace or remove other components to perform a maintenance action. Economic dependence means that performing joint maintenance can save money or generate an additional cost compared to individual maintenance action. In stochastic dependency, a failure in one component impacts a failure distribution of another component or considers that in a system are common causes of failure that cause simultaneous failures (Kobbacy and Murthy, 2008). In this paper, we are interested in exploring stochastic dependence.

Antonello et. al 2019, states that methods for identifying failure dependency in systems are not well explored in literature, because in general this information is assumed to be known. However, in a multicomponent system composed of different items and most of these designs and supplied by different suppliers, the failure dependence only will be better knowledge with a time of operation.

Based on the advances of Industry 4.0, there is an increased interest in literature and industry applications about the use of new information processing technologies applied to industrial processes, equipment, and products (Diez-Olivan et. al. 2019). From a monitored process, data-driven modeling could be building and extract relevant information to support maintenance decisions. In this context, the data-based prognosis is gradually gaining attention in different industrial sectors.

In recent literature, there is an increasing interest in the use of data-mining to develop methodologies for maintenance planning. Following, we present some recent works. Diez-Olivan et. al. 2019, presented an 
interesting review of machine learning for industrial prognosis and highlighted tendencies and challenges in this field. Nguyen and Medjaher 2019 proposed an interesting dynamic predictive maintenance framework for failure prognostics and validated the framework proposed with a real application. Antonello et. al. 2019, studied database alarms of CERN (European Centre for Nuclear Research) and proposed a methodology for identifying failure behaviors. Zhang et al 2019, proposed an association rule mining method to predictive operational problems of building heating, ventilation, and air conditioning (HVAC) systems. Huang et. al. 2019 proposed an approach to evaluate the machine preventive replacement problem considering a serial production line. Ravi et. al 2019 utilized text mining to identify the main causes of failure in the transformer substation. Silva and Sarae 2019, proposed a methodology with association rule mining and text clustering to identify the causes of low voltage fault in an electricity distribution network.

In this paper, we are interested in identifying stochastic dependence. The objective is to find a dependence on the occurrence of simultaneous failures. For this, we proposed a methodology with six steps using the apriori algorithm and the affinity function to identify failure dependence. Broadly, it considers the alarms from CLP database to identify failure dependence. To our knowledge, the affinity function has not been studied from a failure perspective. This work is useful and important to practice because, with input from failure dependence, the decision-maker can improve maintenance planning.

The remainder of the paper is organized as follows. Section 2, the proposed methodology is presented. Section 3 presents a case study and discusses the results. Finally, Section 4 draws some conclusions and management implications.

\section{Determine dependence betweens components based on affinity analysis using apriori algorithm}

The methodology proposed to the identification of dependence in complex systems is composed of six steps, demonstrated in Figure 1.

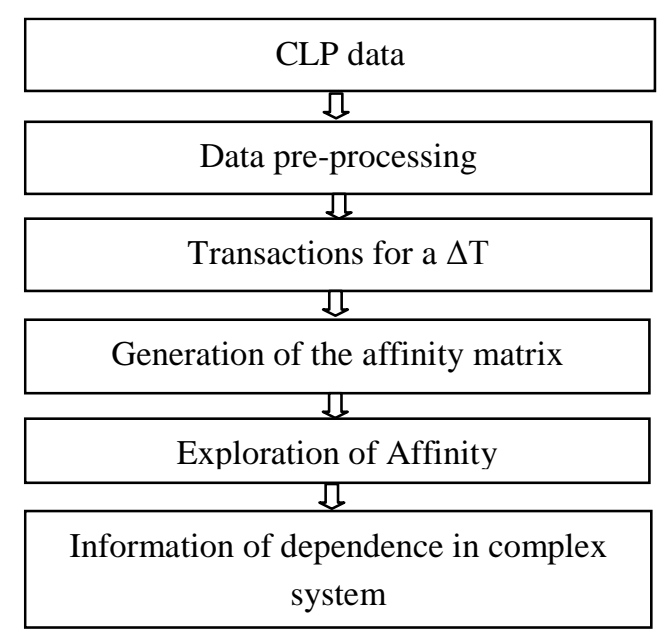

Figure 1. Proposed Methodology

In the first step, data from CLP is extracted to a specified time interval. The interval will depend on the system studied. In most cases, data from CLP will contain some information that will not be necessary for the definition of affinity between components and will need data pre-processing. The data pre-processing concentrate on the extract from database information of interest to building affinity analysis. In this step will separate all alarms occurrence with their description, time of occurrence and machine, to generate a data frame like in Figure 2.

\begin{tabular}{|c|c|l|c|c|}
\hline & Code & \multicolumn{1}{|c|}{ Description } & Time & Machine \\
\hline 0 & 510308 & Porte coulissante gauche non fermée & $2015-01-0700: 42: 15$ & PLC \\
\hline 1 & 510309 & Porte coulissante droite non fermée & $2015-01-0700: 42: 15$ & PLC \\
\hline 2 & 600914 & Accouplement d'alimentation en fluides FS1 non serré & $2015-01-0700: 44: 42$ & PLC \\
\hline 3 & 700205 & Equilibrage de poids surtempérature huile hydraulique & $2015-01-0700: 47: 57$ & PLC \\
\hline
\end{tabular}

Figure 2 
With information from the data frame of step 2 is possible to define the transactions in a time interval. The number of alarms is represented by, $A=\left\{\mathrm{a}^{1}, \mathrm{a}^{2}, \mathrm{a}^{3}, \mathrm{a}^{\mathrm{N}}\right\}$. With the code and time of occurrence of each alarm, we can extract from the database all occurrences associated with a time interval $\Delta T$. We can define transactions in a delta time interval and group all occurrences in a specified delta time $(\Delta T)$.

$$
T R(\Delta T)=\left\{\begin{array}{c}
T(\Delta T) \leftarrow \text { all alarms } A \text { that occurs }\left[T_{0}+\Delta T\right] \\
0 \text { otherwise }
\end{array}\right\}
$$

After the transactions code, the database is formed by transactions in delta time, like in Figure 3

\begin{tabular}{|l|c|c|c|c|c|}
\hline$\Delta \mathrm{T}_{1}$ & 700339 & 700340 & 600112 & 510011 & $\left(\mathrm{a}^{\mathrm{N}}\right.$ alarm code $)$ \\
\hline$\Delta \mathrm{T}_{2}$ & 601011 & 510008 & 510011 & 510012 & $\left(\mathrm{a}^{\mathrm{N}}\right.$ alarm code $)$ \\
\hline$\Delta \mathrm{T}_{3}$ & 27002 & 10621 & 27006 & 600914 & $\left(\mathrm{a}^{\mathrm{N}}\right.$ alarm code $)$ \\
\hline$\Delta \mathrm{T}_{4}$ & 16907 & 6413 & 300951 & 601114 & $\left(\mathrm{a}^{\mathrm{N}}\right.$ alarm code $)$ \\
\hline
\end{tabular}

Figure 3

After obtained the transactions by time is possible to define affinity analysis. The objective with affinity analysis is to calculate a measure of similarity between a pair of transactions by compare pair a pair of all codes of alarms. For this purpose, we use the affinity function proposed by Aggarwal et. al. 2002. The affinity between two alarms $\mathrm{a}^{1}$ and $\mathrm{a}^{2}$ is described by equation 1 that describes the ratio of the transactions containing both $\mathrm{a}^{1}$ and $\mathrm{a}^{2}$ to the transactions containing at last one of the alarms.

$$
A\left(a^{1}, a^{2}\right)=\frac{\sup \left(\left\{a^{1}, a^{2}\right\}\right)}{\sup \left(\left\{a^{1}\right\}\right)+\sup \left(\left\{a^{2}\right\}\right)-\sup \left(\left\{a^{1}, a^{2}\right\}\right)}
$$

With equation 1 is possible to generate affinity matrix and compare all alarms to determine the dependence in failure between components. In step five for exploration of affinity, the analyst, together with decisionmaker, will define the value of affinity " $\alpha$ " to considerate a dependence in the system, for example, in the matrix of affinity, select all values equal or superior to 0.4 . After defining " $\alpha$ " value, it is possible in step six to generate a final matrix with information on dependence in the system.

\section{Case study}

For a case study, we used the same database as (Liu et al., 2018). The study of (Liu et al, 2018) makes a predictive analysis by association rules, our study in this paper is a different perspective where we propose a descriptive study to find dependence between failures.

The CLP data extracted is composed of 500000 lines of registers of alarms from January to December of 2015 in an Excel file with 12 columns. In the first step, we use Python to read Excel file and selected four columns of interest (Code, description, time and machine). After select columns of interest, we deleted all inconsistent characters present in the data file, were deleted 3334 lines with inconsistent characters. In the sequence, we set time column to datetime in Python and ordered the column time by time occurrence. After that, we checked and removed repetitive alarms, were removed 482215 lines with repeated occurrence. At the end, the preprocessed datafile has 14451 lines of alarms with 151 different codes of alarms.

In step three we define a time interval for transactions, this time interval can be defined by a specialist or based on some information about the system in analysis, for example the time of transactions can be set by the interest of planning maintenance actions. In this paper we evaluate transactions for one day, five days and seven days. After the results of transactions and applied the Equations (2), for this study, we analysis results with $\alpha \geq 0.6$ to 1 to extract the knowledge of interest. The value of $\alpha$ can be defined with the decision-maker to represent the system studied and the applicability of affinity analysis.

Figure 4 compares the number of codes with a least one affinity with other code by ranging alfa value of 0.6 to 1 for transactions of one day, five days and seven days. We see that with an increase of affinity value is 
expected a reduce in number of codes with higher affinity. Is interesting to analysis that has a greater number of codes with affinity, demonstrating the importance of the study of affinity in the system analyzed.

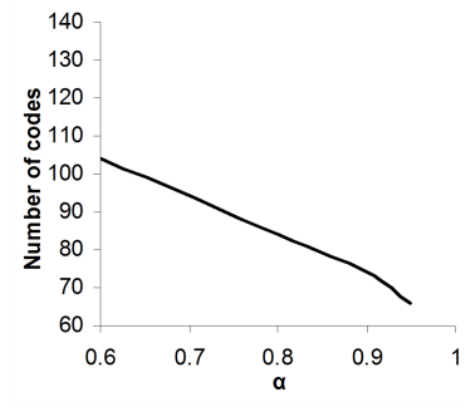

a)

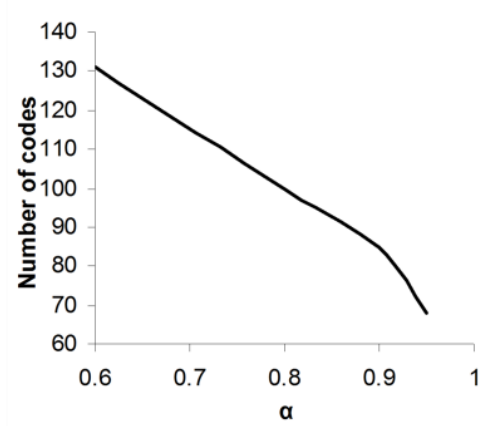

b)

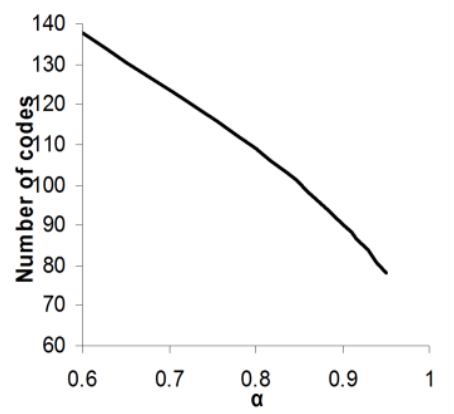

c)

Fig. 4. Number of codes that have at least one affinity result with alpha 0.6 to 1 . a) Transactions for one day; b) Transactions for five days; c) Transactions for seven days

We can analysis in (Table 1) the affinity between a group of 15 codes in seven days of transactions and $\alpha$ $\geq 0.6$.

Table 1 . The affinity between codes.

\begin{tabular}{rrrrrrr}
\hline \multicolumn{7}{c}{ Codes } \\
\hline 16922 & 0.846 & 0.769 & 0.692 & 0.714 & 0.692 & 0.714 \\
510012 & 0.929 & 0.857 & 0.786 & 0.800 & 0.786 & 0.800 \\
510309 & 0.786 & 0.714 & 0.643 & 0.786 & 0.643 & 0.786 \\
601115 & 0.929 & 0.857 & 0.786 & 0.929 & 0.786 & 0.929 \\
67834 & 0.923 & 0.846 & 0.917 & 0.786 & 0.917 & 0.786 \\
700146 & 0.769 & 0.692 & 0.615 & 0.643 & 0.615 & 0.643 \\
700333 & 0.769 & 0.833 & 0.909 & 0.769 & 0.909 & 0.769 \\
700436 & 0.769 & 0.692 & 0.750 & 0.643 & 0.750 & 0.643 \\
701957 & 0.929 & 0.857 & 0.786 & 0.929 & 0.786 & 0.929 \\
\hline
\end{tabular}

In general we can see (Table 2) the results from affinity between codes, for example, code 67834 has an affinity result of 0.923 with code 10208. The results with codes from CLP is an interesting perspective for reliability studies because some results of dependence are difficult to predict at the design stage. With operations data, the results of interactions between components could be better evaluated. With the analysis of affinity, the decision-maker can evaluate all codes and the value of affinity.

\section{Implications for practice maintenance management}

Our results described in practical maintenance management implications:

- With the information of affinity, the maintenance decision-maker can focus the attention in some codes and don't need attention in all codes.

- Is possible to improve the control of maintenance planning by grouping some maintenance actions.

- Where the affinity has a high-value, the analyst can study the purchase of spare parts together and explore the economy of scale.

- Affinity information is important for a postponed decision because a postponed in one component with high affinity will impact in another component. 
- Affinity information is a possible input for the opportunistic maintenance model.

- Scheduling maintenance action can use the information of affinity for prioritizing the next actions.

We present in Table 2 a summary of the affinity applicability in maintenance and reliability studies.

Table 2. Summary of affinity applicability.

\begin{tabular}{ll}
\hline Maintenance Modeling & \multicolumn{1}{c}{ Description for practical } \\
\hline 1 Opportunistic Maintenance & $\begin{array}{l}\text { Through affinity results, the analyst can use dependence of failure } \\
\text { for application opportunistic maintenance model, in other words, } \\
\text { if one maintenance action is performed in one component with } \\
\text { failure dependence an action in another component would be } \\
\text { performed. }\end{array}$ \\
3 Group maintenance & $\begin{array}{l}\text { The analyst can use the information of affinity to planning group } \\
\text { maintenance actions. }\end{array}$ \\
& $\begin{array}{l}\text { In supply chain management studies an aggregation of purchase } \\
\text { of items is a knowledge strategy that generates an economy of } \\
\text { scale. With the information of affinity is possible to evaluate } \\
\text { aggregation of purchase of spare parts. }\end{array}$ \\
\hline
\end{tabular}

\section{Conclusions}

We study a failure dependence between components using CLP data, our finds a considerable number of codes that have a great affinity value. This results is interesting because it provides information to maintenance decision-maker that can assist in planning maintenance actions. For future point of investigation we are looking for building a model that considers spare parts management where affinity information is used to aggregate spare parts orders and achieve economies of scale. Other interest point in spare parts management is about forecast of spare parts, with information of failure dependence is possible evaluated forecast of one component and purchase components with failure dependence together. The limitations affinity measure alone cannot be used for decision-maker this is an input for future maintenance models.

\section{Acknowledgement}

The work has been supported by Capes/Cofecub project number (88881.191793/2018-01)

\section{REFERENCES}

ALBERTO DIEZ-OLIVAN, JAVIER DEL SER, DIEGO GALAR, BASILIO SIERRA, 2019 Data fusion and machine learning for industrial prognosis: Trends and perspectives towards Industry 4.0, Information Fusion, 50, 92-111.

BIN LIU, PHUC DO, BENOIT IUNG, MIN XIE, FLAVIEN PEYSSON, MAYANK JHA 2018, A study on the use of discrete event data for prognostics and health management: discovery of association rules, European Conference of the Prognostics and Health Management Society.

CHEN ZHANG, WEI GAO, TAO YANG, SHENG GUO 2019 Opportunistic maintenance strategy for wind turbines considering weather conditions and spare parts inventory management, Renewable Energy, 133, 703-711.

CHARU C. AGGARWAL, CECILIA PROCOPIUC, AND PHILIP S. YU 2002 Finding localized associations in market basket data, IEEE Trans. on Knowledge and Data Engineering, 14(1):51--62.)

CHAOBO ZHANG, XUE XUE, YANG ZHAO, XUEJUN ZHANG, TINGTING LI 2019 An improved association rule mining-based method for revealing operational problems of building heating, ventilation and air conditioning (HVAC) systems, Applied Energy, 253. C. SILVA AND M. SARAEE, 2019 Understanding Causes of Low Voltage (LV) Faults in Electricity Distribution Network Using Association Rule Mining and Text Clustering, IEEE International Conference on Environment and Electrical Engineering and 2019 IEEE Industrial and Commercial Power Systems Europe, 1-6. 
FEDERICO ANTONELLO, PIERO BARALDI, AHMED SHOKRY, ENRICO ZIO, UGO GENTILE, LUIGI SERIO 2019. DataDriven Extraction of Association Rules of Dependent Abnormal Behaviour Groups. Proceedings of the 29th European Safety and Reliability Conference 10.3850/978-981-11-2724-3_0723-cd.

KOBBACY, K.; MURTHY, D.2008. Complex System Maintenance Handbook. 10.1007/978-1-84800-011-7.

MELIKE ERDOĞAN, İHSAN KAYA, 2020 A systematic approach to evaluate risks and failures of public transport systems with a real case study for bus rapid system in Istanbul, Sustainable Cities and Society, 53.

RAVI, N. N., MOHD DRUS, S., KRISHNAN, P. S., \& LAILA ABDUL GHANI, N. 2019. Substation transformer failure analysis through text mining. In ISCAIE 2019 - 2019 IEEE Symposium on Computer Applications and Industrial Electronics, $293-298$.

THOMAS KALINOWSKI, JASON MATTHEWS, HAMISH WATERER, 2019 Scheduling of maintenance windows in a mining supply chain rail network, Computers \& Operations Research,104670.

OĞUZHAN YAVUZ, ERSIN DOĞAN, ERGÜN CARUS, AHMET GÖRGÜLÜ, 2019 Reliability Centered Maintenance Practices in Food Industry, Procedia Computer Science, 158, 227-234.

CHIARA VIANELLO, MARIA FRANCESCA MILAZZO, GIUSEPPE MASCHIO 2019 Cost-benefit analysis approach for the management of industrial safety in chemical and petrochemical industry, Journal of Loss Prevention in the Process Industries, 58, 116123.

WENJIE DONG, SIFENG LIU, YANGYANG DU 2019 Optimal periodic maintenance policies for a parallel redundant system with component dependencies, Computers \& Industrial Engineering, 138. 